have the right to interpret and implement TRIPS in ways that places public health before trade. But large pharmaceutical companies in the United States and Europe have seen risks to their profits in the Doha declaration. With the public gaze fixed on TRIPS and the WTO they have encouraged the proliferation of bilateral trade agreements that contain intellectual property standards that are much stronger than those to be found in TRIPS.

The Australian-US agreement follows the template that US negotiators use for intellectual property in all such trade negotiations. Compulsory licensing of patents is prohibited except in three circumstances (TRIPS permits compulsory licensing in any circumstances if certain conditions are met). Provisions exist that require US standards of exclusive protection for test data that are submitted as part of the process for gaining marketing approval for pharmaceutical products (TRIPS simply requires its members to protect against unfair commercial use and does not specify a period of protection). Other provisions require parties to offer patent term extensions for pharmaceuticals (not required by TRIPS). On the important issue of parallel trade the Australian-US agreement gives the patent owners greater control over the importation or re-importation of their products. TRIPS expressly steers away from setting a standard on parallel trade.

Some of the greatest risks to Australia, however, may come from the procedures to resolve disputes. The United States and Australia could take different views of Australia's obligation to provide an "independent review" of decisions made by the Pharmaceutical Benefits Advisory Committee, because the meaning of this term has not been specified. The fate of Australia's pharmaceutical benefits scheme could come to lie in the hands of a three member trade panel set up under the trade agreement. If Australia lost and did not comply with the judgment of the panel the United States could retaliate by suspending the benefits to Australia in other sectors affected by the trade agreement, putting pressure on the Australian government to make concessions on drug listing and pricing. Noteworthy here is the fact that Australia has agreed to a procedure to resolve disputes that allows for the possibility of non-governmental per- sons or entities to make submissions. The US pharmaceutical industry, and its lawyers, will no doubt see an opportunity here.

The United States offers no room for negotiation on intellectual property in trade agreements. The law in the United States requires that the country's trade negotiators bring back US standards of intellectual property protection. A committee, which advises Congress on intellectual property and trade, vets the intellectual property chapter in each trade agreement. The committee's membership includes Eli Lilly, Merck, Pfizer, the Pharmaceutical Research and Manufacturers of America, and the Biotechnology Industry Organization. ${ }^{4}$

Bilateral trade agreements and TRIPS together provide the US pharmaceutical industry with a means of strengthening and enforcing patent monopolies globally. They are a covert form of private governance that threatens to undermine hard won public gains in health regulation around the world. The United States is currently negotiating, or is about to start negotiations, with 13 other countries. Countries entering into such arrangements are engaged in a high stakes gamble with their public health systems.

Peter Drahos professor of law

Research School of Social Sciences, Australian National University, ACT 0200, Australia

David Henry professor of clinical pharmacology

School of Medical Practice and Population Health, University of Newcastle, NSW 2308, Australia

(mddah@mail.newcastle.edu.au)

Competing interests: DH has a contract with Wyeth Consumer Products (USA) to review adverse effects of non-steroidal anti-inflammatory drugs and cyclo-oxygenase 2 inhibitors.

Australian Department of Foreign Affairs and Trade. Australia-United States Free Trade Agreement. www.dfatgov.au/trade/negotiations/us fta/ States Free Trade Agreement. Www.dfat.go

2 Henry DA, Birkett D. Changes to the pharmaceutical benefits scheme. Med JAust 2001;174:209-10.

3 World Trade Organization. Declaration on the TRIPS agreement and public health. Fourth WTO Ministerial Conference, Doha, Qatar, 9-14 November 2001. http://www.wto.org/english/thewto_e/minist_e/ min01_e/mindecl_trips_e.htm (accessed 11 May 2004).

4 The US-Australia Free Trade Agreement (FTA). The intellectual property provisions report of the Industry Functional Advisory Committee on Intellectual Property. Rights for trade policy matters (IFAC-3). wwwustrov/new/fta Australia/advisor/ifac03.pdf (accessed 17 Mar 2004).

\title{
Cervical screening
}

\section{Recent changes in policy regarding age and frequency are a poor use of resources}

$\mathrm{T}$ Two expensive healthcare practices have recently been endorsed as policy in England and Wales. ${ }^{1}$ One is continuing to invite women over 50 for cervical screening; the other is shortening the screening interval from five years to three for younger women. National decisions on single issues disregard competing needs and force local decision makers to neglect other, more pressing, problems.

To inform its decision the NHS cervical screening programme commissioned a case-control analysis. ${ }^{2}$ The difference between three yearly and five yearly screening is too small to measure, which is why we are having to use estimates, despite a huge natural experiment involv- ing widely differing screening intervals throughout the nation and worldwide. The analysis estimated that, for women under 40 , the risk reduction is $30 \%$ with five yearly screening and $41 \%$ with three yearly screening. ${ }^{2}$ For women aged $40-54$ years it is $63 \%$ and $69 \%$ respectively. The paper mentioned that three yearly screening costs $60 \%$ to $66 \%$ more than five yearly, and harm from over-diagnosis and over-treatment increases as screening interval decreases. This seems to have had no influence on the recommendations.

What does the new guidance mean for a typical local programme? The Avon programme offers five yearly screening to 250000 eligible women. Each year 59000 
women are tested, of whom 39000 are aged 25-49. Switching to three yearly intervals means nine routine tests by age 50 instead of six. Allowing for the number already having tests for follow up, the actual change in workload for women aged $25-49$ will be around $40 \%$, or 15500 additional women screened each year, together with consequent investigations, treatments, and counselling. At a conservative estimate, with liquid based cytology, of $£ 25$ (\$46; €36) per woman per year, ${ }^{4}$ this will cost an extra $£ 385000$ each year.

The estimates from the commissioned case-control study $^{2}$ suggest this could at best add one woman to the existing 24 women annually (assuming proportional share of national benefit) in whom death from cervical cancer is prevented by our local programme. ${ }^{5}$ Given known problems with case-control analyses it could be less. $^{6}$ With five yearly screening, for each death prevented at least 150 women have abnormal results, and at least 50 are treated. ${ }^{7}$ During any one year in Avon 3000 women aged 25-49 receive abnormal results. ${ }^{3}$ Changing to three yearly screening could add another 1000 women to this group.

So for districts efficiently regulating a five yearly programme the new policy requires diversion of $£ 385000$ annually into an activity that possibly helps one, and adds 1000 to the "worried sick" category. If the NHS were flush with money and no more beneficial activities were in the queue needing funding then this would be acceptable. But there is no spare money and there are other unmet needs.

How unstoppable is three yearly screening? Avon dealt with it in 1987, described its approach in the $B M J$ in $1991,{ }^{8}$ and has been cited as an example of good practice. ${ }^{9}$ During 15 years with a strict five year interval, returning non-indicated tests to the sender, we receive perhaps three queries a year from women, their partners, their members of parliament, or the press. We respond promptly, with a full explanation, and have never encountered disagreement. I have attended many meetings, seminars, and workshops with women's groups to discuss the issue. Always there is keen interest and real readiness to understand the prioritisation issues we face in health care.

The new guidance recommends no screening for women under 25. This is welcome, as the harm to benefit ratio makes screening unethical; for one woman who could be helped by screening in this age group there are tens of thousands who have abnormal results. Controlling this work will help offset the extra cost of three yearly screening. Stopping routine screening beyond 50 would also help, but the NHS cervical screening programme has not sanctioned this. It takes 17793 three yearly tests to detect one new high grade abnormality in well screened women over $50,{ }^{10}$ and at most one death is prevented for each 36 high grades. ${ }^{7}$ To help one person older than 50 through routine five yearly screening therefore takes 420000 tests, costing over $£ 8 \mathrm{~m}$.

Suppose you are faced with the decision about investing $£ 385000$ annually to benefit your local population. You can prevent one death every 22 years by routine five yearly screening beyond age 50 , one death a year and harm an extra 1000 by switching to three yearly screening under 50 , or 10 deaths a year through support that helps smokers stop, ${ }^{11}$ and have enough spare to provide first rate nursing care and family support at home for 183 patients facing death from cancer. ${ }^{12}$

Which would you choose?

Angela E Raffle consultant in public health

Bristol North Primary Care Trust, Bristol BS2 8EE

(angela.raffle@bristolnorth-pct.nhs.uk)

Competing interests: None declared.

1 NHS Cervical Screening Programme. Modernising the NHS cervical screen. NHS Cervical Screening Programme, 22 October 2003 2003)

2 Sasieni P, Adams J, Cuzick J. Benefit of cervical screening at different ages: evidence from the UK audit of screening histories. $\mathrm{Br} J$ Cancer 2003;89:88-93.

3 Department of Health. Local KC53 statistics 2002/03. Avon primary care support agency. London: $\mathrm{DoH}, 2003$

NHS Cervical Screening Programme. How much does the programme cost and how is it funded? www.cancerscreening.nhs.uk/cervical index.html\#cost (accessed 27 Oct 2003).

Quinn M, Babb P.Jones J, Allen E. Effect of screening on incidence of and mortality from cancer of cervix in England: evaluation based on routinely collected statistics. BMJ 1999;318:904-8.

Moss SM. Case-control studies of screening. Int J Epidemiol 1991;20:1-6.

7 Raffle AE, Alden B, Quinn M, Babb PJ, Brett MT. Outcomes of screening Raffle AE, Alden B, Quinn M, Babb PJ, Brett MI. Outcomes of screening to prevent cancer: analysis of cumulative incidence of cervical abnorn
ity and modelling of cases and deaths prevented. BMJ 2003;326:901.

ity and modelling of cases and deaths prevented. BMJ 2003;326:901.
Raffle AE, Alden B, Mackenzie EF. Six years' audit of laboratory workload Raffle AE, Alden B, Mackenzie EF. Six years' audit of laboratory workload
and rates of referral for colposcopy in a cervical screening programme in three districts. BMJ 1990;301:907-11

9 National Audit Office. Performance of the NHS cervical screening programme in England. London, Stationery Office, 1998.

10 Duncan ID. Guidelines for clinical practice and programme management. Oxford: NHS Cervical Screening Programme, 1992.

1 Joint Annual Report from the Directors of Public Health. The health of Brist Annual Report from the Directors of Public Healh. The health of Bristol 2002. Bristol North and Bristol South and West Primary Care

12 Avon Palliative Care Service for Home Support and Culturally Appropriate Care. Report for primary care trusts: October 2001-November 2002 Bristol: Bristol North Primary Care Trust, 2003. www.aswcs.nhs.uk/ supportivecare/APCreport.pdf (accessed 19 Jan 2004).

\section{NICE guidance on newer drugs for epilepsy in adults}

\section{Individualisation of therapy remains the key to successful treatment}

W ith the introduction of felbamate, gabapentin, lamotrigine, levetiracetam, oxcarbazepine, tiagabine, topiramate, vigabatrin, and zonisamide, the number of antiepileptic drugs marketed in different parts of the world has virtually trebled between 1989 and 2002. ${ }^{1}$ The use of newer antiepileptic drugs is increasing steadily. In 2002 new antiepileptic drugs accounted for $20 \%$ of total

prescriptions and for $69 \%$ of total costs for anti- epileptic drugs in the United Kingdom (£99m of $£ 142 \mathrm{~m}){ }^{2}$ Is the shift towards new antiepileptic drugs justified, and what are the indications for these drugs in the modern treatment of epilepsy? These questions are addressed in the latest guidance from the National Institute for Clinical Excellence (NICE). ${ }^{2}$

The guidance, which is based on data from randomised trials, other published information, and feedback from professional, specialist, patient, and 